\title{
Catecholamine surge and lung function after delivery
}

\author{
G FAXELIUS, K HÄGNEVIK, H LAGERCRANTZ, B LUNDELL, AND L IRESTEDT
}

Department of Paediatrics, Department of Anaesthesiology, and Department of Obstetrics and Gynaecology, Karolinska Hospital; Department of Neurophysiology, Karolinska Institute, Stockholm, Sweden

SUMMARY Lung function was measured at 30 minutes and again at 2 hours after birth in 12 infants delivered vaginally, in 15 infants delivered by elective caesarean section under general anaesthesia (GA), and in 15 delivered under epidural anaesthesia (EDA). Umbilical arterial blood was analysed for $\mathrm{pH}$ and for concentrations of catecholamines and cortisol. No important differences in gestational age, birthweight, Apgar scores, or haematocrit were found among the three groups. Tidal volume and minute ventilation measured 30 minutes after birth were lower in infants delivered by caesarean section than in those delivered vaginally and at 2 hours the tidal volume was still lower in the babies delivered by caesarean section than in those delivered vaginally. Dynamic compliance was lower at 30 minutes in the group that had a caesarean section than in the vaginal group, and this difference was significant at two hours. Tidal volume, minute ventilation, and dynamic compliance in the GA and EDA groups did not differ. The catecholamine and cortisol concentrations at birth were higher in the vaginal group than in the group delivered by caesarean section. Two hours after birth there was a significant correlation $(r=0.84)$ between the catecholamine concentrations of the infants born vaginally and lung compliance. The lower dynamic lung compliance in infants delivered by elective caesarean section might be explained by delayed absorption of liquid in the lung due to lack of catecholamine surge.

Infants delivered by caesarean section suffer more often from transient tachypnoea and hyaline membrane disease than infants delivered vaginally. ${ }^{1-4}$ One explanation for this may be that infants delivered by caesarsean section are not subjected to compression of the thoracic cage with the resultant elimination of lung fluid. Milner et al. ${ }^{56}$ showed that the thoracic gas volumes of infants delivered vaginally are higher than those of infants delivered by caesarean section, and they interpreted this as due to an excess of lung fluid in infants delivered by caesarean section. Recent experimental and clinical studies, however, have pointed to the importance of catecholamines in the respiratory adaptation of the newborn infant. ${ }^{7}$ It has been shown that during labour the fetus increases its catecholamine release. $^{8-10}$ Walters and Olver ${ }^{11}$ showed that adrenaline initiates absorption of liquid in the lung in fetal sheep and Lawson et al. ${ }^{12}$ found that catecholamines also enhance surfactant secretion. During vaginal delivery the catecholamine concentration is considerably higher than during elective caesarean section, ${ }^{13}$ and the type of maternal anaesthesia may also influence fetal catecholamine release. ${ }^{13}$ Our study was undertaken to investigate the possible influence of the mode of delivery and maternal anaesthesia on early neonatal lung function, and to determine the relation, if any, between the catecholamine surge and respiratory adaptation.

\section{Patients}

All the infants in the study were born at term in uncomplicated deliveries, and their mothers had normal pregnancies. Their development, assessed according to a modified Dubowitz score, was appropriate for gestational age, but infants with an umbilical arterial $\mathrm{pH}<\mathbf{7 \cdot 2 4}$ at birth were excluded.

Three groups of infants were studied (Table 1). One group comprised 15 infants born by elective caesarean section under general anaesthesia (GA), a second consisted of 15 infants also born by elective caesarean section but under epidural anaesthesia (EDA), and the third group of 12 infants was delivered vaginally after normal spontaneous onset of labour. There were no important differences in gestational age or birthweight among the three groups. The indications for caesarean section were cephalopelvic disproportion, breech position, or an earlier caesarean section. In a few instances caesarean section was performed for psychological reasons. The anaesthetic procedure in the two groups that 
Table 1 Gestational age, birthweight, Apgar score, and umbilical artery $\mathrm{pH}$ in three groups of infants delivered by elective caesarean section under general $(G A)$ or epidural anaesthesia $(E D A)$, and by vaginal delivery $(V A G)$ (mean values $\pm 1 S D)$

\begin{tabular}{|c|c|c|c|c|c|}
\hline \multirow[t]{2}{*}{ Group } & \multirow{2}{*}{$\begin{array}{l}\text { Gestational age } \\
\text { (weeks) }\end{array}$} & \multirow{2}{*}{$\begin{array}{l}\text { Birthweight } \\
(g)\end{array}$} & \multicolumn{2}{|c|}{ Apgar score } & \multirow[t]{2}{*}{$p H$} \\
\hline & & & $I \mathrm{~min}$ & $5 \mathrm{~min}$ & \\
\hline $\begin{array}{l}\text { GA }(n=15) \\
\text { EDA }(n=15) \\
\text { VAG }(n=12)\end{array}$ & $\begin{array}{l}38 \cdot 7 \pm 1 \cdot 2 \\
39 \cdot 3 \pm 1 \cdot 1 \\
39 \cdot 6 \pm 1 \cdot 1\end{array}$ & $\begin{array}{l}3410 \pm 494 \\
3320 \pm 341 \\
3536 \pm 342\end{array}$ & $\begin{array}{l}8 \cdot 7 \pm 0 \cdot 7 \\
9 \cdot 1 \pm 0 \cdot 3 \\
8 \cdot 9 \pm 0 \cdot 3\end{array}$ & $\begin{array}{r}9.7 \pm 0.5 \\
10.0 \pm 0.0 \\
9.8 \pm 0.4\end{array}$ & $\left.\begin{array}{l}7.32 \pm 0.03 \\
7.32 \pm 0.04 \\
7 \cdot 29 \pm 0.05\end{array}\right\}$ \\
\hline
\end{tabular}

had a caesarean section has been described. ${ }^{13}$ In the group delivered vaginally the following analgesics were administered $-100 \mathrm{mg}$ of pethidine ( 8 mothers) in combination with $\mathrm{N}_{2} \mathrm{O}$ (4 mothers) and pudendal block (11 mothers).

The umbilical cord was clamped within five seconds of birth and analysis of blood gases, haematocrit, and catecholamine and cortisol concentrations were made on samples of umbilical arterial blood collected from the doubly clamped cord. ${ }^{13}$ Lung compliance and blood pressure were measured at 30 minutes and at two hours after birth. Informed parental consent was obtained, and the project was approved by the local ethical committee.

\section{Methods}

Measurements were carried out with the infant supine in an open bed incubator. The infant was breathing into a Bennet face mask positioned firmly over the nose and mouth. Flow rate was recorded by mounting a Fleisch pneumotachograph, with a low resistance, in the orifice of the mask and the pressure gradient across the pneumotachograph was recorded by a differential pressure transducer (Elema Schönander EMT 32C). Tidal volumes were obtained by electronic integration of the flow signal and volume calibrations were carried out by injections of a known volume of air into the system. Oesophageal pressure was measured simultaneously by attaching a thin walled latex balloon $(2.5 \times 0.8$ $\mathrm{cm}$ ) to a polyethylene catheter (size 6 FG) which was then passed through the mouth and the tip positioned in the mid third of the oesophagus. The air filled catheter was connected to a pressure transducer (Elema Schönander EMT 34) calibrated against a water column. The signals were recorded on a 4-channel writing recorder (Elema Schönander Mingograph) and calculations made on 8 consecutive breaths. Blood pressure was taken using a Doppler technique (Roche Arteriosonde 1020) on the right arm.

Catecholamines were analysed by high performance liquid chromatography, ${ }^{14}$ and the lowest value which could be detected was $0.1 \mathrm{nmol} / 1$ in a plasma volume of $1 \mathrm{ml}$. Adrenaline values were sometimes below the detectable limit. Plasma cortisol was determined by radioimmunoassay. ${ }^{15}$

The Wilcoxon rank sum test was used to test for significant differences among the groups of infants. Comparisons were made between the two caesarean section groups, and between the vaginal delivery group and the two caesarean section groups. $\mathbf{P}<0.05$ was accepted as significant and these differences only are marked by the corresponding $P$ value.

\section{Results}

There were no differences among Apgar scores in the three groups, but umbilical arterial $\mathrm{pH}$ was lower in the vaginal group than in the caesarean section group (Table 1). Tidal volume and minute ventilation (Table 2) were significantly lower $\mathbf{3 0}$ minutes after

Table 2 Respiratory rate $(f)$, tidal volume $\left(V_{\mathrm{T}}\right)$, and minute ventilation $(V)$ in the three groups, 30 minutes and 2 hours after birth (mean values $\pm 1 S D$ )

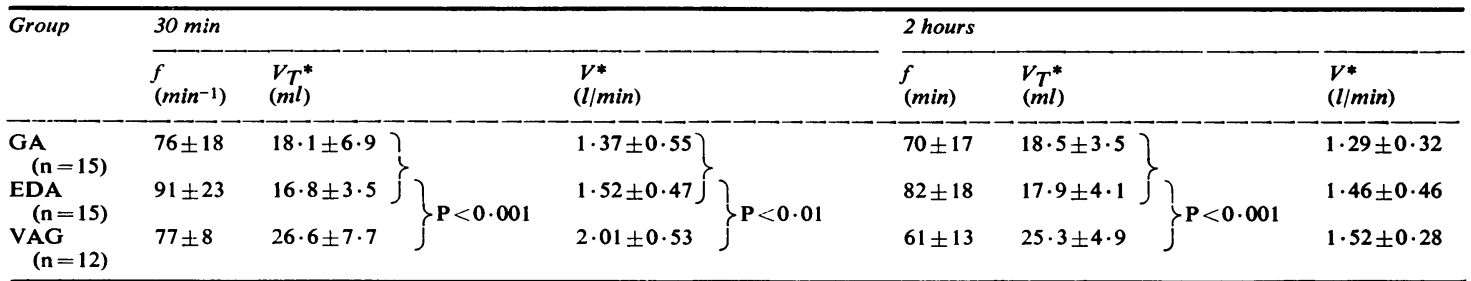

*Expressed at body temperature pressure, saturated with water (BTPS). 
264 Faxelius, Hägnevik, Lagercrantz, Lundell, and Irestedt

Table 3 Dynamic compliance $\left(C_{d y n}\right)$ in the three groups at 30 minutes and 2 hours (mean values $\pm 1 S D$ )

\begin{tabular}{|c|c|c|}
\hline Group & $\begin{array}{l}30 \text { min } \\
\mathrm{Cdyn} \\
\left(\mathrm{ml} / \mathrm{cm} \mathrm{H}_{2} \mathrm{O}\right)\end{array}$ & $\begin{array}{l}2 \text { hours } \\
\mathrm{Cdyn} \\
\left(\mathrm{ml} / \mathrm{cm} \mathrm{H} \mathrm{H}_{2} \mathrm{O}\right)\end{array}$ \\
\hline $\begin{array}{l}\mathrm{GA} \\
(\mathrm{n}=15)\end{array}$ & $2 \cdot 60 \pm 0 \cdot 68$ & $3 \cdot 04 \pm 0.68\}$ \\
\hline $\begin{array}{l}\text { EDA } \\
(n=15)\end{array}$ & $2 \cdot 54 \pm 0 \cdot 88$ & $2.94 \pm 0.96\}\} P<0.01$ \\
\hline $\begin{array}{l}\text { VAG } \\
\qquad(n=12)\end{array}$ & $2 \cdot 97 \pm 0 \cdot 81$ & $3.99 \pm 0 \cdot 84$ \\
\hline
\end{tabular}

birth in infants delivered by caesarean section than in those delivered vaginally. After 2 hours infants delivered by caesarean section still had lower tidal volumes than those born vaginally, but minute ventilation no longer differed significantly. No important differences in respiratory rate were found. Dynamic compliance (Table 3; Figure) was significantly lower in the caesarean section group than in the vaginal delivery group at 2 hours but not at 30 minutes. Values of lung compliance, respiratory rate, tidal volume, and minute ventilation did not differ greatly between the GA group and the EDA group.

No notable difference in haematocrit was found among the groups at either 30 minutes or 2 hours (Table 4). Systolic blood pressure in the vaginal group was higher than in the caesarean section group at 2

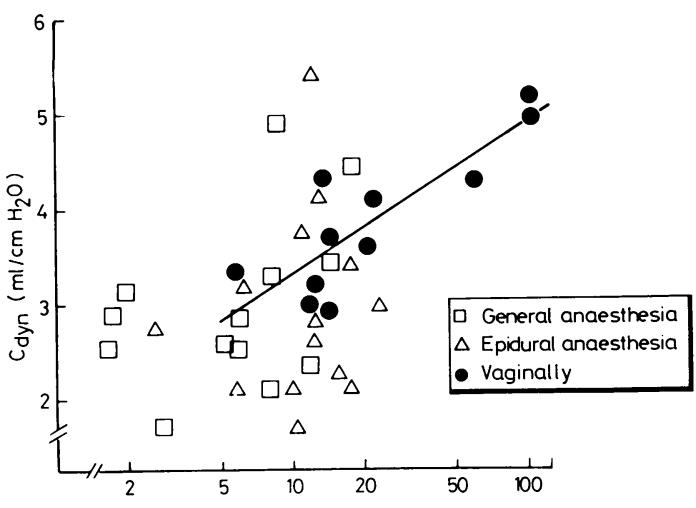

Figure Dynamic compliance $\left(C_{d y n}\right)$ at 2 hours plotted against plasma catecholamine concentration $(C A)$ at birth. The regression line for the vaginally delivered infants only follows the equation: $C_{d y n}=1.72+1.60$ ${ }^{10} \log C A(r=0 \cdot 84, P<0 \cdot 01)$.

hours. At 30 minutes the systolic blood pressure was higher in the EDA group than in the GA group, but at 2 hours no difference was found.

Plasma noradrenaline values in the umbilical arterial blood were significantly higher in the vaginal group than in the two caesarean section groups. Infants belonging to the EDA group had higher

Table 4 Haematocrit at birth (umbilical artery) and blood pressure 30 minutes and 2 hours after birth (Mean values $\pm 1 S D)$

\begin{tabular}{|c|c|c|c|c|c|}
\hline \multirow[t]{2}{*}{ Group } & \multicolumn{3}{|l|}{ Haematocrit $(\%)$} & \multicolumn{2}{|c|}{$\begin{array}{l}\text { Blood pressure } \\
\text { (systolic and diastolic } \mathrm{mm} \mathrm{Hg} \text { ) }\end{array}$} \\
\hline & Umbilical artery & $30 \mathrm{~min}$ & 2 hours & $30 \min$ & 2 hours \\
\hline $\begin{array}{l}\text { GA } \\
(n=15) \\
\operatorname{EDA} \\
(n=15) \\
\text { VAG } \\
(n=12)\end{array}$ & $\begin{array}{l}46 \cdot 4 \pm 2 \cdot 9 \\
47 \cdot 0 \pm 3 \cdot 8 \\
49 \cdot 3 \pm 3 \cdot 9\end{array}$ & $\begin{array}{l}51 \cdot 1 \pm 3 \cdot 9 \\
50 \cdot 2 \pm 5 \cdot 1 \\
51 \cdot 2 \pm 5 \cdot 9\end{array}$ & $\begin{array}{l}53 \cdot 2 \pm 4 \cdot 6 \\
50 \cdot 0 \pm 3 \cdot 5 \\
50 \cdot 2 \pm 5 \cdot 8\end{array}$ & $\left.\begin{array}{l}54 \cdot 8 \pm 6 \cdot 3 \\
33 \cdot 8 \pm 6 \cdot 4 \\
60 \cdot 6 \pm 5 \cdot 9 \\
36 \cdot 0 \pm 6 \cdot 9 \\
58 \cdot 2 \pm 7 \cdot 5 \\
39 \cdot 6 \pm 7 \cdot 4\end{array}\right\} P<0 \cdot 01$ & 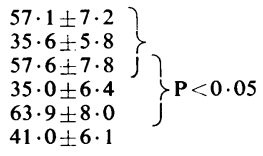 \\
\hline
\end{tabular}

Table 5 Plasma noradrenaline, adrenaline, and cortisol concentration; at birth (umbilical artery) (median values and range)

\begin{tabular}{|c|c|c|c|c|c|c|}
\hline Group & $\begin{array}{l}\text { Noradrenaline } \\
\text { (nmol/l) }\end{array}$ & & $\begin{array}{l}\text { Adrenaline } \\
(\text { nmol/l) }\end{array}$ & & $\begin{array}{l}\text { Cortisol } \\
(\text { nmol/l) }\end{array}$ & \\
\hline \multicolumn{7}{|l|}{ GA } \\
\hline Median & $3 \cdot 4$ & & 0.55 & & 196 & \\
\hline Range & $0 \cdot 38-16 \cdot 14)$ & & $0 \cdot 1-4 \cdot 08$ & & 77-397 ) & \\
\hline No & $\mathrm{n}=15$ & & $\mathrm{n}=14$ & & $n=13$ & \\
\hline EDA & $P<0.05$ & & & $>P<0.05$ & $>P<0.05$ & \\
\hline Median & $8 \cdot 92$ & & $1 \cdot 88$ & & 433 & \\
\hline Range & $2 \cdot 60-20 \cdot 22\}$ & & $0 \cdot 1-5 \cdot 85$ & & $204-828$ & \\
\hline No & $\mathrm{n}=14$ & $>P<0.01$ & $\mathrm{n}=14$ & & $\mathrm{n}=9$ & $>P<0.01$ \\
\hline \multicolumn{7}{|l|}{ VAG } \\
\hline Median & $14 \cdot 07$ & & $2 \cdot 56$ & & 663 & \\
\hline Range & $6 \cdot 91-94 \cdot 30$ & & $0 \cdot 1-17 \cdot 22$ & & 314-1308 & \\
\hline No & $\mathrm{n}=11$ & & $\mathrm{n}=11$ & & $\mathrm{n}=8$ & \\
\hline
\end{tabular}

Conversion: SI to traditional units-cortisol $1 \mathrm{nmol} / \mathrm{l} \approx 27 \cdot 6 \mu \mathrm{g} / 100 \mathrm{ml}$; noradrenaline $1 \mathrm{nmol} / 1 \approx 0 \cdot 169 \mathrm{ng} / \mathrm{ml}$; adrenaline $1 \mathrm{nmol} \approx 0 \cdot 183 \mathrm{ng} / \mathrm{ml}$. 
noradrenaline concentrations than those of the GA group. A corresponding trend was found in the plasma adrenaline concentrations (Table 5). In the vaginal group there was a significant correlation between the catecholamine values in umbilical arterial blood and dynamic lung compliance 2 hours after birth $(r=0 \cdot 84, P<0 \cdot 001)$, but poor correlation in the EDA and GA groups.

Umbilical arterial plasma cortisol values (Table 5) were higher in the vaginal group than in the caesarean section group and were also higher in the EDA group than in the GA group. No correlation was found between the cortisol values and dynamic lung compliance.

\section{Discussion}

Tidal volume, oesophageal pressure, and dynamic lung compliance were measured using conventional pneumotachography and oesophageal balloon methods. Some think that oesophageal balloons may be mechanically deficient ${ }^{16}$ and that the face mask may irritate the infant and affect respiration. On the other hand, this method is rapid, easy to calibrate and use, and acceptable to the parents. The measurement times were chosen so that there was minimal disturbance to the family. Fathers were usually present during the examinations.

Tidal volume and dynamic lung compliance values of the babies in this study were in the same range as those previously reported. ${ }^{41718}$ Infants delivered by caesarean section had significantly lower tidal volumes and minute ventilation 30 minutes postnatally than the vaginally delivered infants. At two hours the difference in tidal volume persisted and the caesarean section babies also showed significantly lower dynamic lung compliance than the vaginal group.

The lower minute ventilation at 30 minutes in newborns delivered by caesarean section may have been caused by the higher arterial $\mathrm{pH}$ at delivery, and possibly by a lower oxygen uptake due to lower sympathoadrenal activity. A further explanation might be a depressive ventilatory effect caused by the general or local anaesthetics administered to the mothers in the caesarean section group. Most mothers in the vaginal delivery group received pethidine, however, which also tends to decrease ventilation. It seems more likely, therefore, that these differences in minute ventilation may be attributed to differences in $\mathrm{pH}$ and sympathoadrenal activity. In a similar study Milner $e t$ al. ${ }^{5}$ found lower thoracic gas volumes, lower tidal volumes, and lower dynamic lung compliance values in infants delivered by caesarean section compared with vaginally delivered infants. Despite minor differences, both studies highlight the difficulty that the infant has in aerating the lungs after elective caesarean section (without labour) compared with normal vaginal delivery. ${ }^{7}$

The classic explanation for the reduced ability to aerate the lungs after caesarean section is that these infants are not subjected to a thoracic squeeze. ${ }^{19}$ Even if this mechanism is important it is probably not the only explanation since a significant difference in lung compliance did not appear until two hours after birth, and since infants born by emergency caesarean section have been reported to have lung volumes and compliance values similar to those born vaginally. ${ }^{20}$ Olver et al. $^{7}$ have suggested that catecholamine concentrations have a role in the absorption of liquid from the lung. Catecholamines may also stimulate surfactant release and so improve aeration of the lungs. ${ }^{12}$ As in a previous study, we found significantly higher catecholamine concentrations after vaginal delivery than after elective caesarean section. ${ }^{13}$ Furthermore, infants delivered vaginally had raised catecholamine concentrations for very much longer than those born by caesarean section, as has been indicated by analyses of catecholamines in fetal scalp blood. ${ }^{8-10}$ The high correlation coefficient between lung compliance and catecholamines after vaginal delivery and the absence of this correlation in infants delivered by caesarean section supports this hypothesis.

The higher neonatal catecholamine values in the EDA group than in the GA group may be caused by the central sympathoadrenal stimulating effect of bupivacaine $^{21}$ - this is probably of a short duration, and does not, therefore, influence neonatal pulmonary adaptation. The cortisol levels were significantly higher in infants delivered vaginally than in those born by caesarean section. Their better lung function may be due to enhanced surfactant synthesis, ${ }^{23}$ but it is unlikely since the maximum effect of cortisol on the lung is seen only after 24-28 hours. ${ }^{15}$ The finding of improved aeration of infants' lungs after maternal treatment with adrenergic $\beta$-receptor agonists ${ }^{22}$ supports the hypothesis that catecholamines may be of major importance in lung function at birth.

We thank Ingrid Dahlin for skilful technical help and Peter Eneroth for the cortisol analyses.

This study was supported by the Swedish Medical Research Council (Grant No 52342520), Expressen's Prenatal Research Foundation, and Sällskapet Barnavård.

\section{References}

1 Usher R H, Allen A C, McLean F H. Risk of respiratory 
distress syndrome related to gestational age, route of delivery, and maternal diabetes. Am J Obstet Gynecol $1971 ; 111$ : 826-32.

2 Brice J E H, Walker C H M. Changing pattern of respiratory distress in newborn. Lancet 1977; ii : 752-4.

3 Faxelius G, Bremme K, Lagercrantz $\mathbf{H}$. Old task revisited -hyaline membrane disease and caesarean section. Eur J Pediatr 1982; 139: 121-4.

4 Hjalmarson O, Krantz M E, Jacobsson B, Sörensen S E. The importance of neonatal asphyxia and caesarean section as risk factors for neonatal respiratory disorders in an unselected population. Acta Paediatr Scand 1982; 71 : 403-8.

5 Milner A D, Saunders R A, Hopkin I E. Effects of delivery by caesarean section on lung mechanics and lung volume in the human neonate. Arch Dis Child 1978; 53: 545-8.

6 Vyas H, Milner A D, Hopkin I E. Intrathoracic pressure and volume changes during the spontaneous onset of respiration in babies born by caesarean section and by vaginal delivery. J Pediatr 1981 ; 99 : 787-91.

7 Olver R E. Of labour and the lungs. Arch Dis Child 1981 ; 56: 659-62.

8 Lagercrantz H, Bistoletti P, Nylund L. Sympathoadrenal activity in the fetus during delivery and at birth. In: Stern L, Salle B, Friis-Hansen B, eds. Intensive care of the newborn. New York: Masson, 1981: 1-12.

9 Nylund L, Lagercrantz H, Lunell N O. Catecholamines in foetal blood during birth in man. J Dev Physiol 1979; 1: 427-30.

10 Artal R, Lam R W, Eliot J, et al. In: Usdin E, Kopin I J, Barchai J, eds. Catecholamines: Basic and clinical frontiers. New York: Pergamon, 1979: 951-3.

11 Walters D V, Olver R E. The role of catecholamines in lung liquid absorption at birth. Pediatr Res 1978; 12: 239-42.

12 Lawson E E, Brown E R, Torday J S, Madansky D L, Taeusch $\mathrm{H} \mathrm{W}, \mathrm{Jr}$. The effect of epinephrine on tracheal fluid flow and surfactant efflux in fetal sheep. Am Rev Respir Dis 1978; 118: 1023-6.

13 Irestedt L, Lagercrantz H, Hjemdahl P, Hãgenvik K, Belfrage P. Fetal and maternal plasma catecholamine levels at elective cesarean section under general or epidural anesthesia versus vaginal delivery. Am J Obstet Gynecol 1982;142: 1004-10.

14 Hjemdahl P, Daleskog M, Kahan T. Determination of plasma catecholamines by high performance liquid chromatography with electrochemical detection: comparison with a radioenzymatic method. Life Sci 1979 25: $131-8$.

15 Gennser G, Ohrlander S, Eneroth P. Fetal cortisol and the initiation of labour in the human. Ciba Found Symp $1977 ; 47$ : 401-27.

16 Ahlström H, Jonson B. Pulmonary mechanics in infants. Methodological aspects. Scand J Respir Dis 1974; 55: 129-40.

17 Lachmann B. Neonatal pulmonary mechanics during spontaneous ventilation. In: Scarpelli E M, Cosmi E V, eds. Reviews in perinatal medicine. Vol. 4. New York: Raven Press, 1981 : 381-419.

18 Geubelle F, Karlberg P, Koch G, Lind J, Wallgren G, Wegelius G. Laération du poumon chez le nouveau-né. Biol Neonate 1959; 1 : 169-210.

19 Karlberg $P$. The adaptive changes in the immediate postnatal period with particular reference to respiration. $J$ Pediatr 1960; 56: 585-604.

20 Boon A W, Milner A D, Hopkins I E. Lung volumes and lung mechanics in babies born vaginally and by elective and emergency lower segmental cesarean section.J Pediatr $1981 ; 98: 812-5$.

21 Covino B G, Vassallo H G. Local anesthetics. Mechanisms of action and clinical use. New York: Grune \& Stratton, 1976: 136

22 Bergman B, Hedner T, Lundborg P. Pressure-volume relationship and fluid content in fetal rabbit lung after $\beta$-receptor-stimulating drugs. Pediatr Res 1980; 14: 1067-70.

23 Talbert L M, Pearlman W H, Potter H D. Maternal and fetal serum levels of total cortisol and cortisone, unbound cortisol, and corticosteroid-binding globulin in vaginal delivery and cesarean section. Am J Obstet Gynecol 1977; 129: 781-7.

Correspondence to Dr H Lagercrantz, Department of Paediatrics, Karolinska Hospital, S-104 01 Stockholm, Sweden.

Received 27 January 1983 